\title{
An Epidemiological Study of Psychiatric Cases in a Rural Community of Nepal
}

\author{
Khattri JB, ${ }^{I^{*}}$ Poudel BM, ${ }^{2}$ Thapa ${ }^{1},{ }^{1}$ Godar ST, ${ }^{3}$ Tirkey $S,{ }^{1}$ Ramesh $K,{ }^{1}$ Chakrabortty PK ${ }^{1}$ \\ ${ }^{1}$ Department of Psychiatry, Manipal Teaching Hospital, Pokhara, Nepal, ${ }^{2}$ Transitional Year Resident, Maryland General \\ Hospital, University of Maryland Medical System, ${ }^{3}$ Department of Opthalmology, Manipal Teaching Hospital, Pokhara, \\ Nepal
}

\author{
*Corresponding Author: \\ Dr. Jai Bahadur Khattri \\ Assistant Professor \\ Dept. of Psychiatry \\ Manipal College of Medical Sciences, Pokhara, Nepal. \\ Email:jai_khattri@yahoo.com
}

\section{Citation}

Khattri JB, Poudel BM, Thapa P, Godar ST, Tirkey S, Ramesh K, Chakrabortty PK. An Epidemiological Study of Psychiatric Cases in a Rural Community of Nepal. Nepal Journal of Medical Sciences 2013;2(1):52-6.

\begin{abstract}
Background: Psychiatric cases are widespread in rural communities of Nepal and there is scarcity of data. The present work was undertaken to study the psychiatric cases and its association with different sociodemographic variables.
\end{abstract}

Methods: A house to house survey was done with simple random method $(n=261)$ in Kusmi Village Development Committee of Baglung District. A semi-structures proforma was used to record the socio-demographic variables and General Health Questinnaire-12 (GHQ-12) was administered to assess the psychiatric cases.

Results: The overall prevalence of psychiatric cases was found to be 37.5 percent. The psychiatric cases were found more in age above 30 years, in males and in other caste (Dalit/Nepali). The maximum number of cases was also elicited in unskilled workers, married group and people who were using alcohol.

Conclusion: The study concludes that there is high prevalence of psychiatric cases in rural community in Nepal. This also calls the need to strengthen the mental health services in the rural community and to address the risk factors associated with psychiatric cases.

Keywords: Prevalence; epidemiology; risk factors

\section{Background:}

$\mathrm{E}_{\text {pidemiology of the psychiatric illness lags behind }}$ other branches of epidemiology due to many reasons. This may be due to difficulties encountered in conceptualizing, diagnosing, defining a case, sampling, selecting an instrument, lack of resources and stigma. ${ }^{1}$ A major challenge for epidemiologists working in psychiatry field is to increase the relevance of their research with regard to their counterparts in preventive medicine and to the policy makers. ${ }^{1}$ Researchers have expressed reservations about the comparisons of various epidemiological studies because of methodological differences. However, one has to rely on the available studies to generalize the findings.

Psychiatric disorders are common but many of them are under-recognized and under-treated in the population because of various reasons. ${ }^{2-5}$ National health policy does 
not give priority to the psychiatric service and mental health in Nepal. ${ }^{6,7}$ This may be due to paucity of information about psychiatric cases in rural community setting in Nepal. Therefore, this study was conducted to find out the prevalence and correlates of psychiatric cases in the rural community. Providing accurate data about the prevalence of mental disorder in the Nepalese rural community would help to justify the allocation of resources and planning of health services.

\section{Methods:}

This study was conducted in rural setting i.e., in the Kusmi Village Development Committee (VDC) of Baglung, a mountain district in Nepal. House to house survey was done and 261 individuals of age 16 or more were randomly selected for the study. The Kusmi VDC had a total population of 3346 (Male: 1495; Female 1851) according to 2001 national census. $^{8}$ The average household size is 5.74 and total numbers of household is $583 .{ }^{8}$ The survey was conducted for three month between the month of January to March in the year 2012. The socio-demographic data sheet was filled up of all the respondents and General health Questionnaire -12 (GHQ-12) (Nepalese Version) ${ }^{9}$ was administered.

The GHQ-12 was used in this study as its validity is wellestablished internationally ${ }^{10-11}$ and most importantly, in a rural community setting in Nepal. ${ }^{9}$ The GHQ is needed for the identification of likely cases or high risk individuals amongst large populations. ${ }^{12}$ It is widely used in different studies across the world. ${ }^{13-19}$ GHQ has a sensitivity $85.58 \%$, specificity $74.79 \%$, positive predictive value $86.66 \%$ and negative predictive value $85 \%$ in the Nepalese population. ${ }^{9}$ GHQ was introduced by Goldberg in 1978 as a screening instrument. Since then, it has been translated into 38 different languages, testament to the validity and reliability of the questionnaire. ${ }^{16}$ The instrument has four versions based on the number of items; GHQ-60, GHQ-30, GHQ-28 and the shortest version GHQ-12. Each item is accompanied by four responses, typically being 'not at all', 'no more than usual', 'rather more than usual' and 'much more than usual'. There are two recommended methods for scoring the GHQ. The first scoring method is "Likert scale" method ranged from 0 to 3 respectively. The second scoring method was "binary scoring" method (with the two least symptomatic answers scoring 0 and the two most symptomatic answers scoring 1 - i.e. 0-0-1-1). The cases threshold is 3 for the 12item version. The shortened version work was found to be as reliable as the long version in detecting distress. ${ }^{15}$ It was also used in diversified population i.e., in student ${ }^{11}$ and also, in young populations in the community. ${ }^{10}$ Furthermore it is simple, easy to understand, short and straightforward to complete.

The individual scoring more than or equal to 3 by "binary scoring" method (0-0-1-1) were labelled as psychiatric cases in the current study.

\section{Results:}

Table 1 shows the distribution of the respondent of different socio-demographic profile with the psychiatric cases. The overall prevalence was found to be 37.5 percent. Majority of the cases were above the age of 30 years. More males (46.1\%) then females $(30.8 \%)$ were found to be suffering from psychiatric problem. The prevalence were found more in others caste (Dalit/Nepali; 75.8\%) then the upper caste. Similarly, cases were found more in unskilled worker. Also, $47.0 \%$ of the married populations were found to be psychiatric case while the unmarried constituted about 24.3 $\%$. While showing the distribution of the respondent on the basis of use of alcohol, psychiatric prevalence was found to be $65.9 \%$ while cases were $31.3 \%$ in the individual who were not using alcohol. The association of different sociodemographic profile with the psychiatric cases was found to be statistically significant.

Table 1: Socio-demographic and psychiatric cases of the population $(n=261)$

\begin{tabular}{|c|c|c|c|c|c|c|c|c|}
\hline \multirow{2}{*}{\multicolumn{2}{|c|}{$\begin{array}{c}\text { Socio-demographic } \\
\text { profile }\end{array}$}} & \multicolumn{2}{|c|}{$\begin{array}{c}\text { Psychiatric } \\
\text { Cases }\end{array}$} & \multirow{3}{*}{$\begin{array}{c}\text { Total } \\
81\end{array}$} & \multirow{3}{*}{$\begin{array}{c}\begin{array}{c}\% \text { of } \\
\text { cases }\end{array} \\
18.5\end{array}$} & \multirow[t]{3}{*}{$\begin{array}{l}\text { Chi } \\
\text { value }\end{array}$} & \multirow[t]{3}{*}{$d f$} & \multirow[t]{3}{*}{$P$ value } \\
\hline & & \multirow{2}{*}{$\begin{array}{c}\text { Yes } \\
15\end{array}$} & \multirow{2}{*}{$\begin{array}{l}\text { No } \\
66\end{array}$} & & & & & \\
\hline AgeGroup & $10-19$ & & & & & & & \\
\hline & $20-29$ & 22 & 41 & 63 & 34.9 & & & \\
\hline & $30-39$ & 22 & 20 & 42 & 52.3 & & & \\
\hline & $40-49$ & 17 & 21 & 38 & 44.7 & 25.19 & 6 & $<0.001$ \\
\hline & $50-59$ & 19 & 13 & 32 & 59.4 & & & \\
\hline & $60-69$ & 2 & 1 & 3 & 66.6 & & & \\
\hline & $>70$ & 1 & 1 & 2 & 50.0 & & & \\
\hline Sex & Female & 45 & 101 & 146 & 30.8 & 6.39 & 1 & 0.011 \\
\hline & Male & 53 & 62 & 115 & 46.1 & & & \\
\hline Caste & Aryan & 74 & 154 & 228 & 32.4 & 20.94 & 2 & $<0.001$ \\
\hline & Mongoloid & 2 & 2 & 4 & 50.0 & & & \\
\hline & Others & 22 & 7 & 29 & 75.8 & & & \\
\hline Marital & Unmarried & 26 & 81 & 107 & 24.3 & 14.51 & 2 & 0.001 \\
\hline Status & Married & 72 & 81 & 153 & 47.0 & & & \\
\hline & Widow & 0 & 1 & 1 & 0.0 & & & \\
\hline Occupation & Unemployed & 21 & 83 & 104 & 20.2 & 24.19 & 3 & 0.001 \\
\hline & Unskilled & 70 & 68 & 138 & 50.7 & & & \\
\hline & Semiskilled & 7 & 11 & 18 & 38.9 & & & \\
\hline & Skilled & 0 & 1 & 1 & 0.0 & & & \\
\hline H/Oalcohol & No & 67 & 147 & 214 & 31.3 & 19.73 & 1 & $<0.001$ \\
\hline & Yes & 31 & 16 & 47 & 65.9 & & & \\
\hline TOTAL & & 98 & 163 & 261 & 37.5 & & & \\
\hline
\end{tabular}




\section{Discussion:}

Epidemiological data pertaining to mental illness in a rural community of Nepal are scarce. The difficulties of organizing mental health services in developing countries are made all the greater by inadequacy of information about the extent of illness and disability. These estimates of the extent of psychiatric morbidity in Nepal were based mainly on health centre/hospital figures and not on field surveys which have been proved to be superior to all other methods in this respect. ${ }^{20}$ Very few attempts have been made in Nepal to obtain epidemiological data on mental illness by field studies. In one study, the survey was done in western region of Nepal focusing on the prevalence of "conspicuous psychiatric morbidity" and another study was done to assess the relationship of caste with depression and anxiety in Jumla, Nepal. ${ }^{21}$ The objectives of our study is not matching exactly with any other study done in a rural setting in Nepal. Therefore, the comparisons of our result findings were done mainly with the Indian studies and also with the international studies.

The psychiatric cases by GHQ-12 in the rural setting in the current study were found to be 37.5 percent. The study conducted in the two developing town of western region also found the high prevalence of "conspicuous psychiatric morbidity" of $35.4 \%$ by Self- Rating Questionnaire (SRQ) in Nepal. ${ }^{4}$ The another study conducted in Jumla found that $33.7 \%$ of the populations were depressed according to Beck's Depression Index (BDI) and 27.7\% are anxious on (Beck's Anxiety Scale (BAI) scale in Nepal. ${ }^{21}$ Many epidemiological studies conducted in India on mental and behavioural disorders report varying prevalence rates, ranging from $9.5^{22}$ to $370^{23}$ per 1000 population. These discrepancies are not specific to the developing countries but are also seen in international studies like Epidemiological Catchment Area (ECA) and the National Co-morbidity Survey (NCS). ${ }^{24,25}$ Epidemiologic research in USA aimed at establishing the incidence and prevalence of mental disorders has evolved in the twentieth century. ${ }^{26}$ In USA, three generations were identified: (a) the period before World War II, in which the median prevalence rate was 36 percent; (b) World War II to the 1970's, in which the median rate was 20 percent; and (c) rates close to 30 percent in the $\mathrm{ECA}^{27}$ and almost 50 percent in the $\mathrm{NCS}^{28}$ were reported.

Maximum cases were reported above the age of 30 years in the current study. Other studies done in India reported the highest prevalence is in the age group 30-44 years and there is a tendency to decline after 45 years. ${ }^{22,29-31}$ However, most of the western studies show a gradual increase of psychiatric disturbance with age. The reason for these falls in the old age in the developing countries may be due to many factors. First, the old people are more secure socially and are protected from psychiatric disturbance. Secondly, the longevity of life is shorter and therefore, the psychiatric conditions commonly seen in old age are less. Lastly, psychiatric symptoms are generally considered as a part of normal aging. However, these areas need more in depth studies to confirm this finding. Short life expectancy of Nepalese population also explains the small sample population above the age of 60 years in our study.

The particular interesting finding of the study is that the psychiatric cases was reported more in males (46.1\%) then in females (30.8\%) in this rural community. Another study ${ }^{32}$ also found higher prevalence in males and he attributed this to increased prevalence of alcohol addiction in males in his study which also explain the higher rate in our study. However, many studies in Nepal and around the globe found the higher rates in females. The another Nepalese study found higher rates in females (42\%) then in males $(28 \%)$ in the two developing town of Nepal. ${ }^{4}$ The ECA survey in US found rates of depression twice as high for females as for males. ${ }^{24}$ The NCS study also found higher prevalence in females $(31.2 \%)$ then males $(27.7 \%){ }^{28}$ The studies conducted in Uttar Pradesh and West Bengal in India also reported higher mental morbidity in females. ${ }^{30,33}$ The reason for these gender difference can be explained by differences in recurrence risk, ${ }^{34}$ drinking habits, expressing emotion, social roles, role performance and role-related strains, as well as professional biases in diagnosis. ${ }^{35}$

Psychiatric morbidity was reported more in others caste (Nepali/Dalit) (75.8\%) then in Aryans in the current sample. The prevalence rate found in mongoloid group cannot be generalized because of less sample size. Two more study conducted in Nepal also found the similar tendency., ${ }^{4,21}$ One study conducted the ethnography research in Nepal and concluded that caste-based disparities in mental health in rural Nepal are statistically mediated by poverty, lack of social support and stressful life events. ${ }^{21}$ The another survey conducted in the two developing town of western region of Nepal found the higher rates of "conspicuous psychiatric morbidity" in occupational group (47.8\%) then in higher caste $(14.15 \%){ }^{4}$ The study conducted in Kerala, India also found increased mental morbidity among the people belonging to scheduled caste in Kerala and attributed this to lower socioeconomic strata of the community. ${ }^{36}$ However, the another study conducted in Tamil Nadu, India found no difference between the two types of caste. ${ }^{37}$ 
Table I also shows that unskilled worker (50.7\%) are suffering from mental illness more often than semiskilled (38.9\%) and unemployed group (20.2\%). The high prevalence of mental illness in semiskilled and unskilled person is also noted by other researchers of this part of the world. . $^{30,32,38}$

Married people $(47.0 \%)$ have a higher rate of psychiatric cases then unmarried group $(24.3 \%)$ in the current sample. The finding of widow/widowers of this study cannot be taken as a true estimate because of negligible sample size. The meta-analysis done in India also found higher prevalence of psychiatric illness in married person then single. ${ }^{39}$ Similar tendency were also reported by other workers in India. ${ }^{30,32,38}$

It was found in this study population that psychiatric illness is more in person who is using the alcohol (65.9\%). This may also explain the higher prevalence of mental illness in males then females in the current study. American researchers suggest that the overall prevalence of alcohol dependence is almost twice as high in those with psychiatric disorders then in the general population. One US study ${ }^{40}$ found that $19.9 \%$ of the general population had one or more psychiatric disorders, but in those with alcohol abuse or dependence the figure rose with $36.6 \%$. Another US study ${ }^{41}$ found that around half of those with a lifetime addiction disorder also had lifetime mental disorder, and vice versa.

\section{Conclusion:}

The study concludes that there is a high prevalence of psychiatric cases in the rural community of Nepal and possible risk factors being the age above 30 years, in males and in married population. The other risk factor noted were doing unskilled job, in other caste (Dalit/Nepali) and the use of alcohol in Nepal. Depending upon the findings of this study, the planning of an adequate mental health program in rural Nepal should be regarded as a national priority. This also emphasizes the need for extending the mental health services into the rural areas in order to reach in the unreached population.

\section{Conflict of interest: nil}

\section{References:}

1. Kessler RC. Psychiatry epidemiology: selected recent advances and future directions. Bull World Health Organ 2000;78:464-74.

2. Murray CL, Lopez AD. The Global Burden of Disease: a comprehensive assessment of mortality and disability from diseases, injuries, and risk factors in 1990 and projected to 2020. Cambridge, MA: Harvard University
Press; 1996.

3. Satcher D. Mental Health: A Report of the Surgeon General. Washington, DC: Government Printing Office, 1999. available at; www.surgeongeneral.gov

4. Upadhyaya KD, Pol K. A mental health prevalence survey in two developing towns of western region. J Nepal Med Assoc 2003;42:328-30.

5. Wang PS, Aguilar-Gaxiola S, Alonso J, et al. Use of mental health services for anxiety, mood, and substance disorders in 17 countries in the WHO world mental health surveys. Lancet 2007;370:841-50.

6. Shakya DR. Mental health in New Nepal. In: Souvenir of the 24th All Nepal Medical Conference (ANEMECON); 2009;62-64.

7. Jha A, Adhikari SR. Mental Health Services in New Nepal. Observations, Objections and Outlooks for the Future. J Nepal Med Assoc 2009;48:185-90.

8. District Development Profile of Nepal with VDC Profile. A Socio-Economic Development Database of Nepal. Mega Publication \& Research Centre Kathmandu, Nepal, 2010/2011.

9. Koirala NR, Regmi SK, Sharma VD, et al. Sensitivity and validity of the General Health Questionnare-12 (GHQ-12) in a rural community setting in Nepal. Nepalese Journal of Psychiatry 1999;1:34-40.

10. Banks MH. Validity of the General Health Questionnaire in a young community sample. Psychol Med 1983;13:349-54.

11. Radanovic Z, Eric LJ. Validity of the General Health Questionnaire in Yugoslav student population. Psychol Med 1983;13:205-7.

12. Goldberg DP, Hillier VF. A scaled version of the General Health Questionnaire. Psychol Med 1979;9:139-45.

13. Abdul Hamid AR, Hatta SMA. Validation study of the Malay language translation of General Health Questionnaire (GHQ-30). Malaysian Psychiatry 1996;2:34-7.

14. Maniam T. Validation of the General Health Questionnaire (GHQ-30) for a Malaysian population. Mal J Psych 1996;4:25-31.

15. Goldberg DP, Gater R, Sartorius N, et al. The validity of two versions of the GHQ in the WHO study of mental illness in general health care. Psychol Med $1997 ; 27: 191-7$. 
16. Jackson C. The General Health Questionnairecomment. Occup Medicine 2007;57:9.

17. Montazeri A, Harrichi AM, Shariati M, et al. The 12-item General Health Questionnaire (GHQ-12): translation and validation study of the Iranian version. Health Qual Life Outcomes 2003;1:66.

18. Quek KF, Low WY, Razack AH, et al. Reliability and validity of the General Health Questionnaire (GHQ12) among urological patients: A Malaysian Study. Psychiatry Clin Neurosci 2001;55:509-13.

19. Nagyova I, Krol B, Szilasiova A, et al. General Health Questionnaire-28: psychometric evaluation of the Slovak version. Studio Pysholoiga 2000;42:351-61.

20. Lin T, Standley CC. The Scope of Epidemiology in Psychiatry. W.H.O., Geneva, 1962.

21. Kohrt BA, Speckman RA, Kunz RD, et al. Culture in psychiatric epidemiology: Using ethnography and multiple mediator model to assess the relationship of caste with depression and anxiety in Nepal. Ann Hum Biol 2009;36:261-80.

22. Surya NC. Mental morbidity in Pondicherry, Transaction, All India Institute of Mental Health, Bangalore, 1964.

23. Carstairs GM, Kapur RL. The Great University of Kota, London: The Hogarth Press; 1976

24. Regier DA, Kaelber CT, Rae DS, et al. Limitations of diagnostic criteria and assessment instruments for mental disorders: implications for research and policy. Arch Gen Psychiatry 1998;55:109-15.

25. Murphy JM, Monson RR, Laird NM, et al. A comparison of diagnostic interviews for depression in the stirling county study: challenges for psychiatric epidemiology. Arch Gen Psychiatry 2000;57:230-6

26. Dohrenwend BP, Dohrenwend BS. Perspectives on the past and future of psychiatric epidemiology: The 1981 Rema Lapouse Lecture. Am J Public Health 1982;72:1271-9.

27. Regier D, Burke J. Psychiatric disorders in the community: the Epidemiologic Catchment Area Study. In Hales R, Frances A (eds): American Psychiatric Association Annual Review. Washington DC: American Psychiatric Press, 1987.

28. Kessler RC, Mc Gonagle KA, Zhao S, et al. Lifetime and 12-month prevalence of DSM-III-R psychiatric disorders in the United States. Arch Gen Psychiatry 1994;51:8-19.

29. Sethi BB, Gupta SC, Rajkumar. 300 urban families: a psychiatric study. Indian J Psychiatry 1967; 9: 280-302.

30. Dube KC.A study of prevalence of mental illness in Uttar Pradesh, India. Acta Psychiatr Scand 1970;56:327-32.

31. Verghese A, Beig A, Senseman LA, et al. A social and psychiatric study of a representative group of families in Vellore town. Indian J Med Res 1973:61:608-20.

32. Thacore VR, Gupta SC, Suraiya M. Psychiatric morbidity in a north Indian community. Br J Psychiatry 1975;126:364-9.

33. Nandi DN, Ajmany S, Ganguli IL, et al. Psychiatric disorders in a rural community in West Bengal: An epidemiological study. Indian J Psychiatry 1975; 17:87-92.

34. Kessler RC, McGonagle KA, Nelson CB, et al. Sex and depression in the National Comorbidity Survey. II: Cohort effects. J Affect Disord 1994;30:15-26.

35. Bebbington $\mathrm{P}$. The origins of sex differences in depression: bridging the gap. Int Rev Psychiatry 1996;8:295-332.

36. Shaji S, Verghese A, Promodu K, et al. Prevalence of priority psychiatric disorders in a rural area in Kerala. Indian J Psychiatry 1995;37:91-96.

37. Mehta P, Joseph A, Verghese A. An epidemiologic study of psychiatric disorders in a rural area in Tamil Nadu. Indian J Psychiatry 1985;27:153-8.

38. Elnagar MN, Maitra $\mathrm{P}$, Rao MN. Mental Health in an Indian rural community. $\mathrm{Br} \mathrm{J}$ Psychiatry 1971;118:499-503.

39. Reddy MV, Chandrashekhar CR. Prevalence of mental and behavioural disorders in India: A meta-analysis. Indian J Psychiatry 1998;40:149-57.

40. Regier DA, Farmer ME, Rae DS, et al. Comorbidity of mental disorders with alcohol and other drug abuse: Results from the Epidemiologic Catchment Area (ECA) study. JAMA 1990;264:2511-8.

41. Kessler RC, Nelson CB, McGonagle KA, et al. The epidemiology of co-occurring addiction and mental disorder: Implications for prevention and service utilization. Am J Orthopsychiatry 1996;66:17-31. 